\title{
Industry 4.0 and Business Policy Development: Strategic Imperatives for SME Performance
}

\author{
Normala S Govindarajo', Dileep Kumar M², Erum Shaikh $^{3 *}$, \\ Mukesh Kumar ${ }^{4}$, Pramod Kumar \\ ${ }^{1}$ Xiamen University Malaysia, Sepang, Malaysia \\ $2,4,5$ Gopal Narayan Singh University, India \\ ${ }^{3}$ The University of Modern Science, Tando Muhammad Khan, Sindh, Pakistan \\ E-mail: 'gnmala@yahoo.com, 2prof.dr.dil@gmail.com, 3erum.shaikh@ums.edu.pk, \\ 4mukesh.kumariims@gmail.com, 5pramodtiwaripatna@gmail.com
}

${ }^{*}$ Corresponding Author

\section{JEL Classification:}

L25

L26

L29

Received: 22 March 2021

Revised: 04 June 2021

Accepted: 09 July 2021

\begin{abstract}
Industry 4.0 presents companies with new prospects to renovate industrial manufacturing processes and increase value creation, has promised several optimizing strategies for improved business performance. The purpose of this research is to examine the relationship between innovation capability and employee capability on organizational performance among Small and Medium Scale industries entrepreneurs. Following a positivist research philosophy with a quantitative, cross-sectional descriptive study design, the study addressed three direct and two indirect relationships in the model. The research followed the expectation Resource-Based View Theory to test the theoretical model. Following stratified random sampling, this research using 384 SME entrepreneurs from the Selangor state of Malaysia. The study applied Smart PLS-SEM to analyze the data. The results show that SME firms' innovation capability and employee capability positively correlate with business performance. The study also shows the partial mediation effect of technology change on innovation capability and business performance and employee capability and business performance. Research extends practical and theoretical implications to the stakeholders of SMEs and businesses.
\end{abstract}

\section{Keywords:}

innovation capability, employee capability, business performance, small and medium scale industries

\section{How to Cite:}

Govindarajo, N. S., Kumar M, D., Shaikh, E., Kumar, M., \& Kumar, P. (2021). Industry 4.0 and Business Policy Development: Strategic Imperatives for SME Performance. Etikonomi, 20(2), 239 - 258. https://doi.org/10.15408/etk.v20i2.20143. 


\section{Introduction}

Industrial Revolution 4.0 is being emphasized among SMEs in Malaysia. SMEs have made and because they are constituting $98.5 \%$ of businesses in Malaysia. Several industries across the globe have well acknowledged the role of emerging technologies. Swift extension of machines and tools with advanced technologies and IoT applications in production and services is well-acknowledged across industries. The industries can use cutting-edge software and networked sensors to schedule, forecast, adapt, and monitor business outcomes. Process Innovation with digitalization has supported several SMEs to enhance the productivity and quality of production. Industrial 4.0 trends like digitalization have enabled real-time data exchange and improve flexibility, pace, efficiency, and quality of output (Thoben et al., 2017; Li et al., 2017). Although SMEs broadly depend on production proficiency for value enhancement, they are expected to gain revenue from Industry 4.0 investments associated with process innovation, acceptance, and execution of Industry 4.0 technologies.

The term industry 4.0 denotes 'fourth industrial revolution. The term reflects its real meaning in transformative aspects related to industry and technology that include the design, production, implementation, operation, and service of manufacturing systems, products, and components. Industry 4.0 digitizes and assimilates procedures and practices upright from corner to corner in the entire organization, from product improvement and purchasing, manufacturing, logistics, and service (Adler \& Shenbar, 1990; Bauernhansl et al., 2014; Jämsä et al., 2011). One of the significant features of Industry 4.0 is the adoption of sophisticated industrial technologies that are coined as Smart Manufacturing. A varied number of product manufacturing processes and services are automated flexibly following the real-time data and exchange of information (Schuh et al., 2017). Enhanced quality of large-scale production by ensuring productivity and flexibility is assured with the digital integration processes. The process innovation and product innovation capability with smart manufacturing have supported customized products at a large scale and balanced way with improved resource utilization (Dalenogare et al., 2018).

Industry 4.0 moreover contemplates the inter-exchange of data and incorporation of the technology-oriented supply chain. By integrating an amalgamation of applications like Artificial Intelligence, machine learning, and predictive analytics, businesses can automate warehouse processes, improve delivery times, efficiently maintain inventory, enhance strategic sourcing relations, and generate new customer data that increase satisfaction and improve sales. This assimilation also allows firms to merge resources in joint production, letting firms' owners emphasize their essential capabilities and product and service innovation, with more value-addition (Chien \& Kuo, 2013).

The advantages envisioned by the smart technology applications in firms also include final products produced out of the smart process (Dalenogare et al., 2018). Smart technologies assist the managers in giving real-time data regarding the production of new products (Tao et al., 2018) by analyzing the customer's well-informed preferences Smart product process with innovation capabilities augment the service quality of the 
current operating system, and it intern support the business development (Porter \& Heppelmann, 2015). A Smart Factory is the outcome of industry 4.0 and is vigorous, and it improves efficiency by communication flows among people, systems, and all resources available in the faculty. SMEs will have to adopt such technology innovation to cope with the local and international market changes.

Previous literature indicates barriers, challenges, and lack of adoption for several reasons like unclear possible benefits, unclear implementation details, and sizeable required investment (Galati \& Bigliardi, 2019; Theorin et al., 2017; Mohamed, 2018). With the increased adoption of Artificial Intelligence and the Internet of Things-based applications, there are still some grey areas linked to the real benefits and requirements and the influence on the business models. Hence, it is necessary to explore the challenges posed to the SMEs in the form of capabilities and resources on the business performances with specific references to small and medium scale business owners.

SMEs have a substantial role in Malaysia's economic development. Collectively SMEs in Malaysia are composed of $98.5 \%$ of all industrial firms (SME, 2020). Based on the statistics in SME annual report 2018-19, the national micro-target under DKN (Dasar Keusahawanan Nasional) 2030 is to increase SME contribution to GDP to 50 $\%$, which was $38.3 \%$ in 2018; generation of employment is raised to $80 \%$, which was $66.2 \%$ in 2018 ; contribution to total export value to $30.0 \%$, which was $17.3 \%$ in 2018; and for the turnover of co-operatives to grow to RM60.0 billion, which was RM40.3 billion in 2018 (SMEAR2018-2019).

To remain competitive in the market, services, manufacturing, and trade-based SMEs face numerous challenges, particularly technology integration, human capability upskilling, hiring, and innovation capabilities. Several SMEs are far behind in the acceptance and execution of Industry 4.0 types of machinery. Since any technology change invites changes in capabilities and resources, the operating models of existing businesses must be relooked into for effective automation during IR 4.0 (Safar et al., 2018; Stentoft et al., 2019). Digitalization invites radical changes in service and manufacturing operations, further necessitating digital literacy, digital competencies, and artificial intelligence capabilities.

Malaysian SMEs are aware of several adaption deficits. SMEs face constraints related to resources to make an effective industrial 4.0 based technology transformation that needs to be studied. Some of the significant threats raised among SMEs in this context include coping with technology change, the need for innovation capabilities and worker capabilities, and subsequent business performance opportunities. The smaller the SMEs are, the greater the threat since they will not cope with the change and make any gain from the digital transformation. Such scenarios open the need for more exploration and action plans for organizing SMEs in a technological and administrative path (Sommer, 2015). Though several studies were conducted in large-scale industrial establishments, there are limited studies focused on SMEs, exploring the intervening effect of technology change in its relationship with innovation capability, employee capability, and business performance. 
Industry 4.0 has developed an ecosystem where there is an integration of evolving technologies. These new technologies are transforming the labor market, particularly in an individual's competencies and abilities to meet the new industrial conditions and requirements. Consequently, there is a requirement for newfound professional profiles. The application of new wave tools and techniques affects equally workers working in firms and the organization itself. Reliant to the business sector, precise skills and individual tasks may differ from one job to another due to the divergence of procedures and methods. Past research on human resources influence indicates that people at work directly positively affect firm performance (McKelvie \& Davidsson, 2009). Based on the Resource-Based View Theory, internally oriented personnel knowledge, unique skills, and capabilities can give the firm a competitive advantage. The human resource department can achieve this objective by recruiting and maintaining a well-trained labor force and managers who will accelerate innovation (Zahra \& Nielsen, 2002). As expected, any changes in the technology will invite corresponding changes in the employee capabilities to handle the new technology and innovation-driven operations. This condition directs that a workforce quality that will be fine-tuned with the technology is an essential factor determining the success of technology change.

Samson et al. (2017) researchers have found Innovation Capability as the significant theme for research. Innovation capability defines as "the way enterprises can generate innovative outputs" (Esterhuizen et al., 2012). Innovation capacity or capability entrenched in the organizational procedures and collective workplace behaviors used by the firm to segregate innovation opportunities, seamlessly share information, encourage discussion, and call for new ideas (McGrath, 2001).

Industry 4.0 developed an aura of a "smart and sensible" automated industrial unit where production systems, employees, commodities, and consumers are associated with each other (Karre et al., 2017). The advent of Industry 4.0 boosts the organization's technological capacities development as one of the highly critical operating forces to ascertain the effectiveness of organizational flexibility into the art of digitization in the production and business environment (Laugsand, 2017). The firms' resource is to be in tune with the required product and service changes expected by the market, and it should be generated from customer appreciation. Several research reports indicate that innovation plays a vital role in determining the growth and competitiveness of any organization (Kim \& Maubourgne, 2005). Nevertheless, a considerable volume of businesses has adopted innovation practice without great accomplishment. In the majority, situation organizations reported an average, very little or no effect with the efforts of their innovations (Wolff \& Pett, 2004). In this context, it is rightly pointed out that a firm's performance is associated with the capability to earn profit and growth to meet the strategic objectives (Hult et al., 2004). Consequently, innovation has become a prerequisite closely knit with the growth, performance, competitiveness, profit maximization, and firm's survival for an extended period (Jiménez \& SanzValle, 2011).

Work and work organizations are substantially changed with the use of technology and technology innovation. SMEs can thus bring substantial improvement in doing 
business by aligning the technology-based innovation with organizational changes like dealing with equipment, managing resources, evaluating environmental protection, stimulating clean production, and better R \& D of new materials and new energy sources (Adepoju et al., 2017). Technology change turned to be the emphasis of considerations across the world. Several technological changes are witnessed by the industrial world, such as cyber-physical systems, the Internet of Things, big data and data analytics, cloud and information technology, robots and automated machinery, 3D printing, simulation, portable devices. A great initiative at the organizational level is in need to cope with the ever-changing work processes with the modern technological assimilation. Organizations are facing challenges related to the acceptance and adoption of technology based on the technology changes. Technology change has created several implications at the managerial level, looking at the projected competencies with its integration into business opportunities. There will be a need for different forms of managerial, diplomatic, and social skills that are in tune with the expected technology changes facilitating decisionmaking processes by accommodating new organizational structures so that employees can perform the tasks and functions effectively.

Jobs in industries are affected by the changes in technological applications, where innovation is widely diffused (Durowoju, 2017). On the contrary, the technology change is considered a threat, where fewer human resources are required to perform the traditional intensive people-oriented tasks. However, the changes based on innovation have enhanced the workflow and facilitated better production effectiveness and efficiency.

Performance can be attributed as the primary indicator in assessing the operation of an organization. The evaluation of performance can be understood from an impartial viewpoint that is more associated with the monetary valuation to the firm's performance in return on equity, return on assets, and growing sales (Shariff et al., 2010). Davood \& Morteza (2012) viewed performance as the ability of a firm to create acceptable outcomes and actions.

Technological change is considered as "the engine of growth." Technology change and the state of technology have an explicit connection to the company, workers, and performance. Besides that, technology, labor, and capital are interrelated. A change in the technology invites corresponding changes in the employee capabilities to handle the new operations. This condition indicates that workforce quality that is fine-tuned with the technology is an essential factor determining the success of technology change. Technologies can lead to increased productivity or performance when combined with other resources effectively by human resources or when done effectively (Dauda \& Akingbade, 2011). Studies have established the relationship between technological development and capability augmentation of employees, which equips them with relevant labor market skills, drives into a firm's performance. This condition specifies that technology change envisages corresponding resource management changes at the organizational level that facilitate organizational performance. Despite these notable studies, less attention has been given to the technology change readiness of SMEs concerning expected changes in employee capabilities. Hence it is argued that a better employee capability facilitated 
by technology change thus extends better among SMEs. The technology understandably changes act as a moderator.

Though the direct relation of Innovation capability on organizational performance is well established, several factors enhance or decrease its influence act as moderators. The researchers inferred that failure to adopt an appropriate new technology or the failure to realign a firm's strategy to the new technology deteriorates the organization's competitive position and further affects its performance. The firm's innovation capability is the most crucial factor for competitive advantage in highly turbulent market conditions. Innovation capability leads organizations to develop innovations continuously to respond to the changing market environment (Slater et al., 2010). It is embedded with all the strategies, systems, and structures that support innovation in an organization (Gloet \& Samson, 2016). Though such claims exist with remarkable studies, less attention has been given to the technology change readiness of SMEs. The firm's performance will be decided by its readiness to fine-tune the required innovation capability with the technology change. A better innovation capability is thus seconded with appropriate technology change at the production level. The technology changes justifiably act as a moderator. Hence the role of technology change is hypothesized as a moderator between innovation capability and organizational performance among SMEs.

The fourth industrial revolution is known as industry 4.0, seeing the progress in the industrial way of doing with the coordinated push for automation, big data, and internet-of-things. Therefore, the purpose of this study is to explore the industrial 4.0 based technology transformation challenges in small and medium-sized service industries, specifically wholesale and retail industries. The question raised in this context is how far the small and medium scale industries are ready to absorb the industrial revolution, which invites innovation capacities with automation, big data, and internet-of-things.

It is hypothesized in this study that the higher the technology change, the higher the competence depletion will lead to a lower level of business performance. A better innovation capability of the organization with the support of Industry 4.0 oriented human skills can reduce the competence depletion of the workforce and enhance business performance. The study applied quantitative research with standardized instruments to analyze the relationship between innovation capabilities and employee capabilities on organizational performance, and the study followed standardized instruments to measure it. The research site was the Klang Valley region of the Selangor state of Malaysia. Study finding provides better insight into the need for innovation capabilities and human resource competencies preparedness towards Industry 4.0 in its adaption to SMEs for better business performance in the Malaysian context.

\section{Methods}

The Resource-Based View theory in Figure 1 delivers a complete view on the efficacy of resource utilization. Resource amalgamation is a vital part of joining the inside and outside an enterprise. When resources are exposed and efficiently used by a 
firm, the value will appear. Applying RBV theory in this research, the employee and innovation capabilities are linked to the organization's technological innovation systems with the changes initiated by industry 4.0 to bring better production processes, product quality, and market orientation (see Figure 2). It is argued in this context that employee capabilities and innovation capabilities determine the control of resource adequacies that would lead to better organizational competence and performance.

Figure 1. Resource Based View Theory

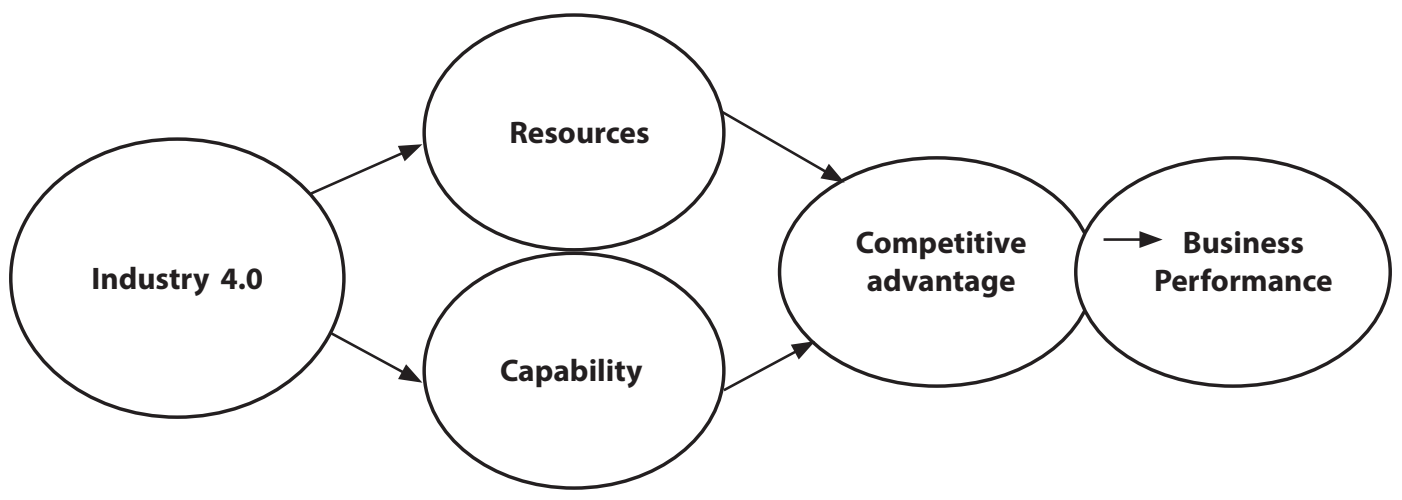

Source: (Barney, 1991)

Figure 2. Resource Based View Theory Integrates into Industry 4.0.

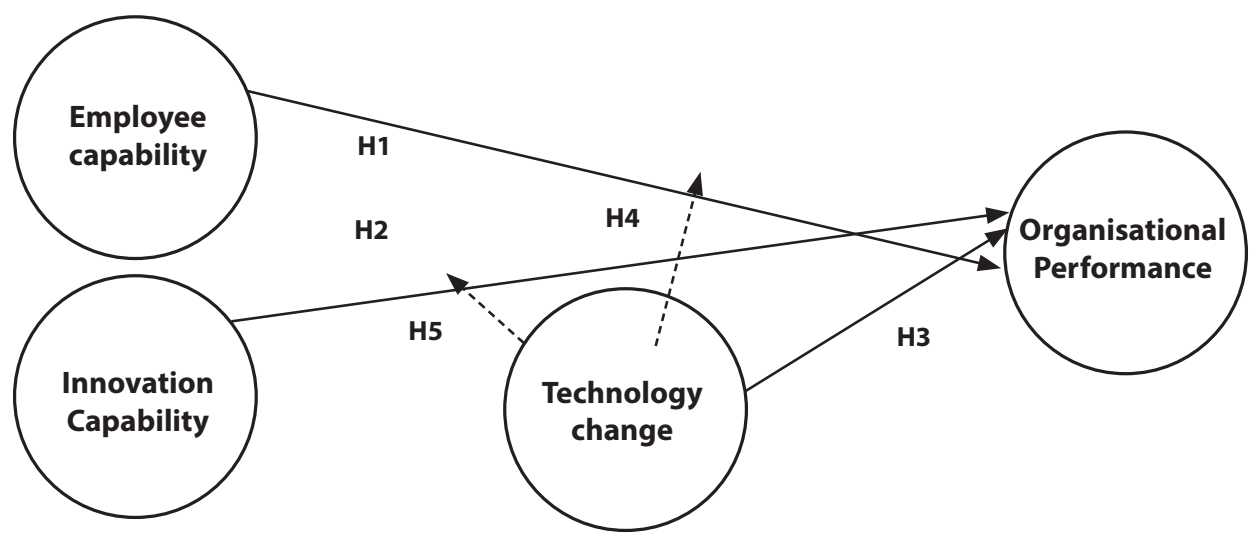

Most of the measurements that have been utilized in this current study were adapted from past-established instruments (see Table 1). The questionnaire is divided into five sections: technology change/disruption (Ryan \& Harrison, 2001, and dimensions from Kaufman (1974), innovation capacity (Tang, 1999; Poolton \& Ismail, 2000; Walker et al., 1996; Bjurwill, 1993; Gobeli \& Brown, 1994; Canfield \& Miller, 1998; Moorman \& Miner, 1998), employee capability (Hosseini \& Kamal, 2012), and organizational performance (Brewer \& Selden, 2000), and all were evaluated with a five-point Likert scale, where a higher score indicates stronger agreement than the lower score.

A sample was drawn from the SMEs directory available from SME Corporation Malaysia that consists of all SMEs in the Klang Valley region of Malaysia. Further, 
SMEs belonging to the service sector were identified and isolated. Finally, SMEs for the wholesale and retail sector were drawn from Selangor, where $19.5 \%$ of the service sectors are located from this state. Sample size can be determined based on the method recommended by Krejcie \& Morgan (1970). This condition is achieved based on Krejcie \& Morgan's (1970) simplistic rule of thumb table for determining sample size from a given population. The study followed stratified random sampling because the sample industries belong to different strata of industrial segmentation (small \& medium), followed by the purposive sampling technique.

Table 1. Measurements

\begin{tabular}{|c|c|c|c|c|c|}
\hline No & Variables & $\begin{array}{l}\text { No. of } \\
\text { Items }\end{array}$ & Scale & $\begin{array}{l}\text { Cronbach's } \\
\text { Alpha }\end{array}$ & Author \\
\hline 1 & $\begin{array}{l}\text { Employee } \\
\text { Knowledge } \\
\text { competence } \\
\text { (capability) }\end{array}$ & 9 & 5 Point & 0.79 & Hosseini \& Kamal (2012). \\
\hline 2 & Innovation Capacity & 23 & 7 Point & 0.80 & $\begin{array}{l}\text { Tang (1999). } \\
\text { Poolton \& Ismail, } 2000 . \\
\text { Walker et al. (1996); Lester et al. } \\
\text { (1998); Bjurwill (1993), Gobeli \& } \\
\text { Brown, (1994), Canfield \& Miller } \\
\text { (1998); Moorman \& Miner (1998) }\end{array}$ \\
\hline 2 & $\begin{array}{l}\text { Technology } \\
\text { disruption }\end{array}$ & 14 & 7 Point & 0.81 & $\begin{array}{l}\text { Ryan \& Harrison (2001) } \\
\text { (dimensions from Kaufman (1974) }\end{array}$ \\
\hline 4 & $\begin{array}{l}\text { Organisational } \\
\text { performance }\end{array}$ & 6 & 5 Point & 0.80 & Brewer \& Selden (2000) \\
\hline
\end{tabular}

The purposive sampling has engaged due to the unavailability of the already existing list of SMEs. Also, there is a crossover of many firms based on the latest SME definitions of Malaysia. Those small-scale entrepreneurs with at least five years of experience running the organization were considered for the study. Such selection aims to ensure that the respondents can provide adequate information on the impact of technology change in the SMEs where they are working. The researcher collected 384 questionnaires back from 425 sets of questionnaires distributed.

Table 2. Summary of Cronbach's Alphas RHO_A, Composite Reliability, Average Variance Extracted (AVE)

\begin{tabular}{lccccc}
\hline \multicolumn{1}{c}{ Measurement Items } & Item & $\begin{array}{c}\text { Cronbach's } \\
\text { Alpha }\end{array}$ & rho_A & $\begin{array}{c}\text { Composite } \\
\text { Reliability }\end{array}$ & $\begin{array}{c}\text { Average Variance } \\
\text { Extracted (AVE) }\end{array}$ \\
\hline Employee Capability & 14 & 0.812 & 0.910 & 0.920 & 0.799 \\
Innovation Capability & 23 & 0.801 & 0.905 & 0.911 & 0.812 \\
Technology Change & 9 & 0.792 & 0.921 & 0.934 & 0.790 \\
Organisational Performance & 6 & 0.803 & 0.909 & 0.923 & 0.691 \\
\hline
\end{tabular}


The study followed validity analysis to measure the accuracy of the instruments. The content validity did through 10 experts who were elected. All the wordings inside the items are well appraised into their suitability for pilot testing to ensure the item's difficulties and ease. Hair et al. (2014) suggested using the Average Variance Extracted (AVE) as it has become a widespread method. The general rule would be that the AVE of each latent construct needs to be much greater than 0.50 for determining adequate convergent validity (Hair et al., 2014). The following table provides the details of validating the convergent validity on the construct level. Table 2 indicates that all the merits of AVE were in the acceptable range between 0.501 and 0.820 , indicating an adequate convergent validity. Thus, the convergent validity was confirmed in the study.

Table 3. Discriminant Validity - Hetrotait Monotrait Ratio

\begin{tabular}{lcccc}
\hline & $\begin{array}{c}\text { Technology } \\
\text { Change }\end{array}$ & $\begin{array}{c}\text { Innovation } \\
\text { Capability }\end{array}$ & $\begin{array}{c}\text { Employee } \\
\text { Capability }\end{array}$ & $\begin{array}{c}\text { Organisational } \\
\text { Performance }\end{array}$ \\
\hline Employee Capability & & & & \\
Innovation Capability & 0.798 & & \\
Technology Change & 0.801 & 0.811 & \\
Organisational Performance & 0.799 & 0.780 & 0.756 \\
\hline
\end{tabular}

Based on the questionnaire adopted, table 3 shows that the Cronbach's Alpha for the technology disruption is 0.81 , innovation capability is .80 , employee capability is 0.79 , and organizational performance is .80 . Overall scores show that Cronbach's Alpha is exceeding 0.7 (Nunnaly, 1970). Hence, it can be assumed that internal consistency for this questionnaire is good.

\section{Result and Discussion}

\section{Empirical Result}

Table 4 indicates the results of the hypotheses testing using the SmartPLS path model analysis resulted in three important observations: firstly, employee capability has a positive and significant relationship with organizational performance $(\beta=0.456$; $t$ $=2.345)$; hence $\mathrm{H} 1$ is supported. Secondly, the innovation capability has a positive relationship to organisational performance $(\beta=0.421 ; t=2.267)$. Hence $\mathrm{H} 2$ is supported. Besides that, technology change has a positive and significant relationship with organizational performance $(\beta=0.521 ; t=2.891)$. Including employee capability, innovation capability, and technology change into the Smart PLS path model analysis contributes 63.7 percent of the change in the dependent variable. The structural framework from this study shows in Figure 3. 


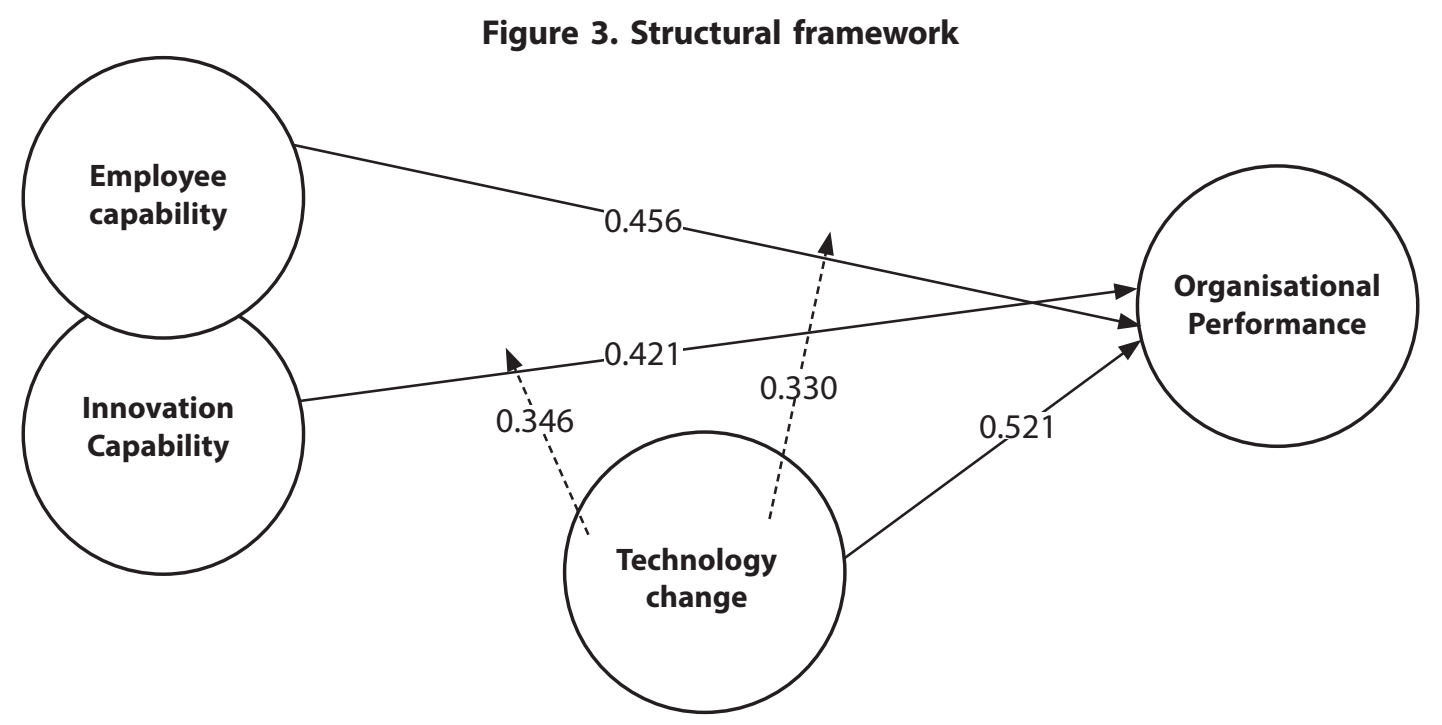

Table 4 Results of Direct Hypothesis

\begin{tabular}{ccccc}
\hline Relationship & Beta $(\boldsymbol{\beta})$ & $\boldsymbol{t}$-Value & $\boldsymbol{p}$-Value & $\mathrm{R}^{2}$ Value \\
\hline Employee Capability $\rightarrow$ & Organizational Performance 0.456 & 2.345 & 0.040 & \multirow{2}{*}{0.637} \\
Innovation Capability $\rightarrow$ & Organizational Performance 0.421 & 2.267 & 0.032 & \\
Technology Change $\rightarrow$ & Organizational Performance 0.521 & 2.891 & 0.034 & \\
\hline
\end{tabular}

Significant level $={ }^{*} p<0.05, t>1.65$

Table 5 shows the test findings of hypotheses 5 and 6. The findings indicate that the indirect relationship between the independent variables (employee capability, innovation capability, and technology change) and the dependent variable (organizational performance) is partially significant. Chin (1998) suggests that the R-squared values of 0.67, 0.33, and 0.19 in PLS-SEM can consider as substantial, moderate, and weak, respectively. Interestingly, the relationship between employee capabilities, innovation capability, and technology change on business performance is reduced but remains significant as complimentary. Followed by the direct and indirect hypothesis testing, the study also applied Stone-Geisser's test to get the predictive relevance to confirm through $\mathrm{Q}$ square values, which is carried out as predetermined. The $\mathrm{Q}^{2}$ is a criterion to measure how well a model predicts the data of omitted cases (Chin, 1998; Hair et al., 2014).

Table 5 Results of Indirect Hypothesis

\begin{tabular}{lccccccc}
\hline Relationships & $\begin{array}{c}\text { Direct } \\
\text { Effect } \boldsymbol{\beta}\end{array}$ & $\begin{array}{c}\boldsymbol{t} \text { - } \\
\text { Value }\end{array}$ & $\begin{array}{c}\text { Significant } \\
(\mathbf{p}>\mathbf{0 . 0 5})\end{array}$ & $\begin{array}{c}\text { Indirect } \\
\text { Effect } \boldsymbol{\beta}\end{array}$ & $\begin{array}{c}\boldsymbol{t} \text { - } \\
\text { Value }\end{array}$ & $\begin{array}{c}\text { Significant } \\
(\mathbf{p}>\mathbf{0 . 0 5})\end{array}$ & Effect \\
\hline $\mathrm{EC} \rightarrow \mathrm{OP}$ & 0.456 & 2.345 & $\begin{array}{c}\text { Yes } \\
(p=0.000)\end{array}$ & 0.346 & 1.928 & $\begin{array}{c}\text { Yes } \\
(p=0.000)\end{array}$ & $\begin{array}{c}\text { Partial Mediation } \\
\text { (Complimentary) }\end{array}$ \\
\hline $\mathrm{IC} \rightarrow \mathrm{OP}$ & 0.421 & 2.267 & $\begin{array}{c}\text { Yes } \\
(p=0.000)\end{array}$ & 0.330 & 1.791 & $\begin{array}{c}\text { Yes } \\
(p=0.000)\end{array}$ & $\begin{array}{c}\text { Partial Mediation } \\
\text { (Complimentary) }\end{array}$ \\
\hline
\end{tabular}


A research model with Q2 statistic (s) greater than zero is considered to have predictive relevance. Furthermore, a research model with higher positive Q2 values suggests more predictive relevance. The test results show that $\mathrm{Q}$ square values are between 0.341 and 0.389 (Hair et al., 2017). The values are above the standard that is more significant than zero (Henseler et al., 2014). Therefore, the findings generally support the predictive relevance of the SmartPLS path model used in this study. Finally, the effect of square size of the relationship between the variables (employee capability, innovation capability, and technology change) ranges from 0.0356 to 0.437 (organizational performance). These values are categorized as small and medium-size effects, as stated by Hair et al. (2017). The value of $\mathrm{f}$ square $=0.02$ is categorized as small, 0.15 as moderate, and 0.35 as large.

\section{Discussion}

The industrial revolution, which is closely knit with industry 4.0, has witnessed several technology changes at the organizational level. A new form of organizational understanding is related to implanting personal capabilities, structures, strategies, resources, and organizational processes. Nevertheless, such invasion of technology disruption, how far has paved better insight into resource management, people management, and business performance, is less researched. This study has investigated the influence of employee capability, innovation capability, and technology change on organizational performance of SMEs in the Malaysian service industry, mainly focused on the retail and wholesale firms and the moderating effect of technology change between employee capabilities, innovation capability on organizational performance. It is well established that there is a strong and positive relationship between employee capability, innovation capability, and technology change on organizational performance. The moderation effect further indicates the partial mediation effect of technology change in its relationship between employee capability, innovation capability, and technology change on organizational performance in SMEs.

Several organizations have started their technology adoption and working in a very competitive environment. The execution of new digital tools and technical know-how is affecting both employees working in businesses and companies. The challenge of the competence context involves a three-factor approach, including the level of the company management, the areas of the production methods, and the kinds of competencies (Erol et al., 2016). Industry 4.0 has thus given a redirection to all types of organizations where the companies must focus on new generation skills and competencies in tune with digitalization (Da Silva et al., 2019). Better integration of employee capabilities will pave better business performance opportunities and is a vital indicator of any organization's success or failure (Sanders et al., 2016).

Operationally rigorous firms have joined a fresh wave of automation and digitization. Such changes will have a significant effect on the skills they require to stay on competitive. There are several strategies before the SMEs to look at to reduce the skills gap and improve business performance. One option is upskilling and reskilling of the existing employees. They can develop skills inside the company by retraining their existing workforces to 
make ready individuals for new positions and tasks. Alternatively, they can adopt a hybrid method by using skilled contract staff to deliver short-term demands while creating the required skills within the company.

The study finding indicated the relationship between employee capabilities and organizational performance. In line with such established relationships, the increased use of technology in day-to-day operations offers an uncomfortable situation of lacking appropriate skills to manage such technologies in SMEs. Progress in technology application has led to skill obsolescence. The degree to which specialists lack updated information or skills essential to sustain adequate performance in their existing or forthcoming work roles (Kaufman, 1974), or there is an inconsistency between an individual's job performance and the fundamental capability level (Mirabile, 1998; Chauhan \& Chauhan 2009; Rita et al., 2012), because of an upgrade of required worker skill level and a shift in types of skills required. The SME sector currently needs a major revamp in the skill sets to cope with the procedural and production process changes.

The innovation capability identifies as the company's capability to produce new technologies, methods, and commodities (Gewe et al., 2016). It is recognized as the company's capacity to obtain, introduce, and develop a new understanding that tacitly permits the organization to accomplish the directed performance. Similarly stipulated to the company's ability to cultivate new goods, processes, competencies, and knowledge on the physical, organizational environment in a constructive manner and utilize it in model formation, permitting the organization to competently obtain targeted performance (Olusula, 2011; Salisu \& Bakar, 2018).

The current research results indicated the relationship between innovation capabilities and organizational performance. Innovation capability directs firms to constantly develop innovations to react to the varying market situation (Slater et al., 2010). It is rooted in all the strategies, systems, and structures that upkeep a firm's innovation (Gloet \& Samson, 2016). Beyond technical innovation, SMEs should increasingly develop their innovation capabilities to lead the organizational performance by providing customer attention and market requirements. Innovation has confirmed a robust and significant relationship with performance. The innovation capacity extends an organization's comprehensive set of capabilities that facilitate and support aligning organizational strategies for better organizational performance.

In general, many SMEs associate digitization with words such as Digital Marketplaces, Platforms, Big Data, Industry 4.0, Digital Manufacturing, Online Marketing, Internet of Things (IoT), websites, and much more. Such changes at the technology level have been highly influencing the day-to-day business processes, and its intern is highly affected by the methodical use of physical forces through various forms of technology. The availability of fine-tuned technology determines the quality and quantity of commodities and services delivered.

Industry 4.0 changes the structure, method, or experience from on-going as predictable or as expected. Modern companies must realign their value chain following 
the technological change for performance. Firms will have to rethink the way they do business. Companies will have to drive the digital transformation of their business to succeed in the new environment. SMEs, however, massive projects generally invite uncontrollable risks. Consequently, several actions and projects require vast supplies of capital, know-how, and time to execute them. Hence, it assumes that projects cannot be carried out purely due to a dearth of resources and capabilities.

The research finding shows a direct relationship between technological change and organizational performance. When a new technology abruptly supersedes the old, disruption occurs, and the entire ecosystem needs to readjust the environmental interaction conditions to suit the new technology. Technology change or disruption has necessitated organizations. The change can destroy the current competence or enhance the capabilities existing in the industry for competitive advantage (Hill \& Rothaermel, 2003). To cope with the dynamics of change, small and medium enterprises should focus their attention on improving their obsolete machinery and other equipment since it is necessary to follow the latest standardized procedures and market expectations.

The research also shows a partial moderating effect between innovation capability and business performance. This result indicates that innovation capability is a more substantial variable with its direct effect on business performance than technology change. SMEs need to investigate current innovation capabilities and fine-tune their organizational culture according to the expected technological change. Innovation capability is of utmost vital constituents for evolving good innovation results within the firm to permit the application of resources and continuous transformation of knowledge and skills into product, process, and system for the benefit of firms and stakeholders. During changes, the firms that facilitate such innovative culture remain ahead of their contestants because such innovation capabilities eventually contribute to organizational performance, marketing performance, and overall financial performance.

The study results will support practitioners and top-level managers to comprehend the concept and role of employee capability and innovation capability during technology changes in SMEs and its effect on organizational performance. It is promising that firms leverage technology, innovation, and employee capabilities to deliver better innovation outcomes and organizational performance. When technology change is widely adopted in SMEs, the company management must look into the employee capabilities in tune with the changes initiated. Any failure to restate the required human capabilities will result in companies turning into remnants of the century, and a vast volume of employees turn outdate due to the lack of skills to compete in the changed business scenario.

Competence depletion is a severe concern for SMEs as they grapple with the everchanging competence requirements to keep up with the technology demands. Innovation is the prerequisite to manage such technological changes. Innovation capabilities in product, process, design, machinery, operations are highly significant in coping with technological changes. The change initiatives at the competence level can bring better business scenarios 
to SMEs. Technology disruption depletes accumulated competence required for the current line and offers competitive opportunities to appropriate competence.

There are some practical decisions for improving the innovation capability ecosystem for SMEs, such as: (1) Integrate innovation into new operating models. (2) Induce big data and artificial intelligence skills. (3) Knowledge of digital marketing and data analytics. (4) Assimilate data analytics into process and product innovation decisionmaking. (5) Support SMEs in adopting ICT and adapt to the digital uprising. (6) Investment increases in idea generation. (7) Follow changing customer needs for better insights. (8) Promote innovative marketing tools or more general innovation marketing. (9) Creating, enabling, and catalyzing business links. (10) Collaborate with suppliers and allied stakeholders for new ideas. (11) Espousal of a customer-focused firm alignment. (12) Commit supplementary resources for innovation. (13) Support the attainment of explicit technological capabilities. (14) Internationalization support to access external markets for their innovative products, processes, or services. (15) Facilitate technology transfer from public research labs and institutions. (16) Captivation of new knowledge traced through external partners. (17) Implement flexible innovation cash schemes. (18) Operational change from simple to more progressive technologies. (19) Facilitate continuous improvements in product quality.

Besides that, the government should take some action to improve the innovation capability for SMEs, such as. (1) Facilitate the ability to innovate. (2) Ensure broad absorptive capacity that integrates external knowledge and adaptive capability. (3) Embrace different management capabilities that spread across all functions. (4) Facilitate service innovation. (5) Locate, engage, and reconfigure external partners. (6) Develop a well-defined set of abilities focused on firms' ecosystems for service innovation. (7) Continuous scanning, filtering, and exploring technologies and $s$ to be analyzed by the focal firm. (8) Immersive and collaborative working skills inducement. (9) Adaptability in the development of new skills and capabilities. (10) Organize co-created workshops between the innovation group and the facilitation team. (11) Flexible, intelligent, and innovative human resources. (12) Support activities address creativity thinking and product conception. (13) Induce the research capabilities. (14) Develop inter-personnel attitudes and communications for the exchange of ideas in groups. (15) Induce leadership skills for exploration, ideation, adaption, and transfer. (16) Encourage awareness of the significance of innovation-based supervision skills. (17) Problem-solving competencies that enable productivity improvements. (18) Increasing Intellectual Property Rights related skills in SMEs through education and training and making.

Resources are in the form of knowledge, infrastructural assets, digital technologies, human capital, and other tangible and intangible factors owned or controlled by the firms. From this theoretical framework, SME firms comprise a variety of assets and individuals that retain competencies. The harmonious influences created by their permutations lead to most in the means of creating competitive advantage. Essential resources positively affect various performance features for consistently functioning SME activities. 
This study follows the resource-based view (RBV) to develop the research frame, to align the observations with SMEs' competitive advantage and organizational performance. SMEs should pool the resources in the form of tangible and intangible assets. SMEs should take initiatives in bringing tangible resources. In the form of the latest technology, technical know-how, and algorithms from outside in the wake of technology disruption and that should be aligned with the intangible assets which include the resources as capabilities viz., intangible bundles of abilities and skills of a business, that are distinct from assets (Ethiraj et al., 2005), developed inside the business over time, fine-tuned with the latest technological disruption.

The current research thus once again proves the application of resource-based view (RBV) theory to inform the practitioners and scholars to investigate the tangible and intangible resources that can lead to better organizational and market performances. The performance of SMEs is crucial for their development and existence within an industry. This performance is receiving more attention in the current global market environment than ever before (Jämsä et al., 2011). The research throws a better understanding of the thoughtful situation of technology disruption and the resultant business performance problems the SMEs face during industry 4.0, and it supports better competency preparedness among SMEs in Malaysia for technology changes.

\section{Conclusion}

Industry 4.0 has paved several trends of automation, data exchange in service and production technologies. SMEs are in a perplexing mode to look at technological change with all available resources and capabilities. The study findings establish the strong relationship between the independent variables (employee capability, innovation capability, and technology change) and dependent variables (organizational performance), explaining the impact of technology disruption on the organizational performance of SMEs in Malaysia. The study findings pave better practical briefings to the line managers and HR managers of SMEs in their prominent role in workforce competence building and developing innovation capabilities by ensuring innovative and proactive strategic decisions. During the technology disruption of industry 4.0, it is expected that the SME entrepreneurs should take initiatives to ensure a work culture that uses innovation capabilities of the people and organization for better product and process performance, which will lead to better market performance. The study leaves strategic obligations to the policymakers in drafting sound industrial 4.0 policies for better business performance.

\section{References}

Adepoju, A. O., Olomu, M. O., \& Akinwale, Y. O. (2017). The Impact of Technological Innovation On SME's Profitability In Nigeria, International Journal of Research, Innovation and Commercialisation, 1(1), 74-92.

Adler, P. S., \& Shenbar, A. (1990). Adapting Your Technological Base: The Organizational Challenge. Sloan Management review, 32(1), 25-37. 
Barney, J. (1991). Firm Resources and Sustained Competitive Advantage. Journal of Management, 17, 99-120. https://doi.org/10.1177/014920639101700108.

Bauernhansl, T., Hompel, T.M., \& Vogel-Heuser, B. (Eds). (2014). Industrie 4.0 in Produktion, Automatisierung und Logistik. Springer. Berlin.

Bjurwill, C. (1993). Read and React: The Football Formula. Perceptual and Motor Skills, 76(3), 1383-1386. https://doi.org/10.2466/pms.1993.76.3c.1383.

Brewer, G. A., \& Selden, S. C. (2000). Why Elephants Gallop: Assessing and Predicting Organizational Performance in Federal Agencies. Journal of Public Administration Research and Theory, 10(4), 685-712. https://doi.org/10.1093/oxfordjournals.jpart. a024287.

Canfield, J., \& Miller, J. (1998). Heart at Work: Stories and Strategies for Building Selfesteem and Re-awakening the Soul at Work. McGraw-Hill. Crawfordsville.

Chauhan, S. \& Chauhan, D. (2009). Are You on The Verge of Obsolescence. Indian Journal of Industrial Relations, 44(4), 646-59.

Chien C. F., \& Kuo, R. T. (2011). Beyond Make-or-Buy: Cross-Company ShortTerm Capacity Backup in Semiconductor Industry Ecosystem. Flexible Services and Manufacturing Journal 25, 310-342. https://doi.org/10.1007/s10696-011-9113-4.

Chin, W.W. (1998). The Partial Least Squares Approach for Structural Equation Modelling. In Marcoulides, G. A. (Ed.), Modern Methods for Business Research, pp. 295-336. Lawrence Erlbaum Associates. London.

Da Silva, V. L., Kovaleski, J. L., \& Pagani, R. N. (2019). Technology Transfer and Human Capital in the Industrial 4.0 Scenario: A Theoretical Study. Future Studies Research Journal: Trends and Strategies, 11, 102-12. https://doi.org/10.24023/FutureJournal/ 2175-5825/2019.v11i1.369.

Dalenogare, L. S., Benitez, G. B., Ayala, N. F. \& Frank, A. G. (2018). The Expected Contribution of Industry 4.0 Technologies for Industrial Performance. Industrial Journal of Production Economics, 204(10), 383-394.

Dauda, D. Y., \& Akingbade, W. A. (2011). Technological Change and Employee Performance in Selected Manufacturing Industry in Lagos State of Nigeria. Australian Journal of Business and Management Research, 12(3), 115-127.

Davood, G. \& Morteza, M. (2012). Knowledge Management Capabilities and SMEs Organisational Performance. Journal of Chinese Entrepreneurship, 4(1), 35-44.

Durowoju, S.T. (2017). Impact of Technological Change on Small and medium Enterprises Performance in Lagos state, Economic and Environmental Studies, 17(4), 743-756.

Erol, S., Jäger, A., Hold, P., Ott, K., \& Sihn, W. (2016). Tangible Industry 4.0: A Scenario-Based Approach to Learning for the Future of Production. Procedia CIRP 2016, 54, 13-18. https://doi.org/10.1016/j.procir.2016.03.162.

Esterhuizen, D., Schutte C. S., \& Toi, A. D. (2012). Knowledge Creation Processes as Critical Enablers for Innovation, International Journal of Information Management, 32(4), 354-364. 
Ethiraj, S. K., Kale, P., Krishnan, M. S., \& Singh, J. V. (2005). Where Do Capabilities Come from and How Do They Matter? A Study in the Software Service Industry. Strategic Management Journal, 26(1), 25-45. https://doi.org/10.1002/smj.433.

Galati, F., \& Bigliardi, B. (2019). Industry 4.0: Emerging Themes and Future Research Avenues Using a Text Mining Approach. Computers in Industry, 109, 100-113. https://doi.org/10.1016/j.compind.2019.04.018

Gewe, A. M., Abebe, B. B., Azene, D. K., \& Bayu, F. G. (2016). Local industry Technological Capability Development Using Outsourcing Opportunities. Strategic Outsourcing: An International Journal, 9(3), 287-302. https://doi.org/10.1108/SO02-2016-0005.

Gloet, M., \& Samson, D. (2016). Knowledge Management and Systematic Innovation Capability. International Journal of Knowledge Management, 12(2), 54-72. https:// doi.org/10.4018/IJKM.2016040104.

Gobeli D. H., \& Brown, W. B (1994). Technological Innovation Strategies. Engineering Management Journal, 6(1), 17-23.

Hair J. F., Sarstedt, M., Hopkins, L. \& Kuppelwieser, V. (2014). Partial Least Squares Structural Equation Modelling (PLS-SEM): An Emerging Tool for Business Research. European Business Review, 26(2), 106-121. https://doi.org/10.1108/EBR10-2013-0128.

Hair, J. F., Hult, G. T. M., Ringle, C. M., \& Sarstedt, M. (2017). A Primer on Partial Least Squares Structural Equation Modelling (PLS-SEM) (2nd ed.). Sage Publishing. Thousand Oaks, CA.

Henseler, J., Dijkstra, T. K., Sarstedt, M., Ringle, C. M., Diamantopoulos, A., Straub, D. W. \& Calantone, R. J. (2014). About PLS: Comments on Ronnkko and Evermann (2013). Organizational Research Methods, 17(2), 182-209. https://doi.org/ $10.1177 / 1094428114526928$.

Hill, C. W. L. \& Rothaermel, F. T. (2003). The Performance of Incumbent Firms in the Face of Radical Technological Innovation. The Academy of Management Review, 28(2), 257-274. https://doi.org/10.2307.30040712.

Hosseini, Z., \& Kamal, A. (2012). A Survey on Pre-service and In-service Teacher's Perceptions of Technological Pedagogical Content Knowledge (TPCK). The Malaysian Online Journal of Educational Technology, 1(2), 1-7.

Hult, G. T. M., Hurley, R. F. \& Knight, G. A. (2004). Innovations: Its Antecedents and Impacts on Business Performance. Industrial Marketing Management, 33(2), 429-438. https://doi.org/10.1016/j.indmarman.2003.08.015.

Jämsä, P., Tahtinen, J., Ryan, A., \& Pallari, M. (2011). Sustainable SMEs Network Utilization: The Case of Food Enterprises. Journal of Small Business and Enterprise Development 18(1), 141-156. https://doi.org/10.1108/14626001111106479.

Jiménez, J. D., \& Valle, S. R. (2011). Innovation, Organizational Learning, Performance. Journal of Business Research, 64(4), 408-417. 
Karre, H., Hammer, M., Kleindienst, M., \& Ramsauer, C. (2017). Transition Towards an Industry 4.0 State of The LeanLab at Graz University of Technology. Procedia Manufacturing, 9, 206-213. https://doi.org/10.1016/j.promfg.2017.04.006.

Kaufman, H. G. (1974). Obsolescence and Professional Career Development. AMACOM. New York.

Kim, W. C., \& Maubourgne, R. (2005). Value Innovation: A Leap Into The Blue Ocean. Journal of Business Strategy, 26(4), 22-28.

Krejcie, R. V., \& Morgan, D. W. (1970). Determining Sample Size for Research Activities. Educational and Psychological Measurement, 30(3), 607-610. https://doi.org/10.1177/ 001316447003000308.

Laugsand, E. E. (2017). Industry 4.0: New technologies and potential for increased value creation. Industrial Economics and Technology Management. (Unpublished Dissertation). Norwegian University of Science and Technology.

Lester, R.K., Piore, M.J., \& Malek, K.M. (1998). Interpretive Management: What General Managers can learn from Design. Harvard Business Review, 4(5), 86-96.

Li, G., Hou, Y., \& Wu, A. (2017). Fourth Industrial Revolution: Technological Drivers, Impacts and Coping Methods. Chinese Geographical Science, 27(4), 626e637. https:// doi.org/10.1007/s11769-017-0890-x

McGrath, R. D. G. (2001). Exploratory Learning, Innovative Capacity and Managerial Oversight. The Academy of Management Journal, 44(1), 118-131. https://doi.org/ $10.2307 / 3069340$.

McKelvie, A., \& Davidsson, P. (2009). From Resource Base to Dynamic Capabilities: An Investigation of New Firms. British Journal of Management, 20(1), 63-80. https:// doi.org/10.1111/j.1467-8551.2008.00613.x.

Mirabile, R. J. (1998). Leadership Competency Development, Competitive Advantage for The Future. Management Development Forum, 1(2), 1-15.

Mohamed, M. (2018). Challenges and Benefits of Industry 4.0: An Overview. International Journal of Supply and Operations Management, 5(3), 256-265. https:// doi.org/10.22034/ 2018.3.7.

Moorman, C., \& Miner. A. S. (1998). The Convergence of Planning and Execution: Improvisation in New Product Development. Journal of Marketing, 62(3), 1-20. https://doi.org/10.1177/002224299806200301.

Nunnally, J. C. (1970). Introduction to Psychological Measurement. McGraw-Hill. New York.

Olusula, O. (2011). Intrinsic Motivation, Job Satisfaction and Self-Efficacy as Predictors of Job Performance of Industrial Workers in Ijebu Zone of Ogun State. The Journal of International Social Research, 4(7), 569-577

Poolton, J., \& Ismail, H. (2000). New Development in Innovation. Journal of Managerial Psychology, 15(8), 795-811. https://doi.org/10.1108/02683940010379350.

Porter, M. E., \& Heppelmann, J. E. (2015) How Smart, Connected Products Are Transforming Companies. Harvard Business Review, 93, 1-37. 
Rita, A., Jere, B., \& David, R. (2012). The Right Skills for the Job? Rethinking Training Policies for Workers. Human Development Perspectives. World Bank. Washington, DC.

Ryan, S., \& Harrison, D. (2000). Considering Social Subsystem Costs and Benefits in Information Technology Investment Decisions: A View from the Field on Anticipated Payoffs. Journal of Management Information Systems, 16(4), 11-40. https://doi.org/10.1080/07421222.2000.11518264.

Safar, L., Sopko, J., Bednar, S., \& Poklemba, R. (2018). Concept of SME Business Model for Industry 4.0 Environment. TEM Journal, 7(3), 626-637. https://doi. org/ 10.18421/TEM73-20.

Salisu, Y., \& Bakar, L. J. A. (2018). Strategic Alliance and the Performance of SMEs in Developing Economies: The Mediating Role of Innovation Strategy. Asian Journal of Multidisciplinary Studies, 6(2), 47-56.

Samson, D., Gloet, M., \& Singh, P. (2017). Systematic Innovation Capability: Evidence from Case Studies and a Large Survey. International Journal of Innovation Management, 21(7), 1-43. https://doi.org/10.1142/S136391961750058X.

Sanders K., \& Yang H. (2016). The HRM Process Approach: The Influence of Employees' Attribution to Explain The HRM - Performance Relationship. Human Resource Management, 55(2), 201-217. https://doi.org/10.1002/hrm.21661.

Schuh, G., Anderl, R., Dumitrescu, R., Krüger, A., ten Hompel, M. (2017). Industrie 4.0 Maturity Index. Managing the Digital Transformation of Companies. Acatech Study. Munich.

Shariff, M. N. M., Peou, C. \& Ali, J. (2010). Moderating Effect of Government Policy on Entrepreneurship and Growth Performance of Small-medium Enterprises in Cambodia. International Journal of Business and Management Science, 3(1). 57-72.

Slater, S. F., Hult, G. T. M., \& Olson, E. M. (2010). Factors Influencing The Relative Importance of Marketing Strategy Creativity and Marketing Strategy Implementation Effectiveness. Industrial Marketing Management, 39(4), 551-559. https://doi.org/10.1016/j.indmarman.2008.03.007.

SME Corp. (2017). Industry 4.0 - SMEs are the Vanguards in Catalysing Change. Retrieved from: http://www.smecorp.gov.my/images/article_KE/viewpoint.pdf, (Retrieved on December 31, 2020).

SME, Corp, (2020). Report on SME Corp. Retrieved 01 24, (2021). Retrieved from: https://www.smecorp.gov.my/index.php/en/policies/2020-02-11-08-01-24/smestatistics

SMEAR2018_2019. (2019). Report on SME Corp. Retrieved from smecorp.gov.my: https:// www.smecorp.gov.my/images/SMEAR/SMEAR2018_2019/final/english/SME\%20 AR\%202018-19\%20Booklet\%20-\%20English\%20Side.pdf

Sommer, L. (2015). Industrial Revolution-Industry 4.0: Are German Manufacturing SMEs The First Victims of This Revolution? Journal of Industrial Engineering and Management, 8(5), 1512-1532. https://doi.org/10.3926/jiem.1470. 
Stentoft, J., Jensen, K. W., Philipsen, K., \& Haug, A. (2019). Drivers and Barriers for Industry 4.0 Readiness and Practice: A SME Perspective with Empirical Evidence. Proceedings of the 52nd Hawaii International Conference on System Sciences, 6, 51555164. https://doi.org/10.24251/hicss.2019.619

Tang, H. K. (1999). An Inventory of Organizational Innovativeness. Technovation, 19(1), 41-51. https://doi.org/10.1016/S0166-4972(98)00077-7.

Tao, F., Qi, Q., Liu, A. \& Kusiak, A. (2018). Data-Driven Smart Manufacturing. Journal of Manufacturing Systems, 48, 157-169. https://doi.org/10.1016/j.jmsy.2018.01.006.

Theorin, A., Bengtsson, K., Provost, J., Lieder, M., Johnsson, C., Lundholm, T., et al. (2017). An event-driven manufacturing information system architecture for Industry 4.0. International Journal of Production Research, 55(5), 1297-1311. https://doi.or g/10.1080/00207543.2016.1201604.

Thoben, K. D., Wiesner, S. A., \& Wuest, T. (2017). Industrie 4.0 and Smart Manufacturing-a Review of Research Issues and Application Examples. International Journal of Automation Technology, 11(1), 1-12. https://doi.org/10.20965/ijat.2017.p0004

Walker H. M., Horner, R. H., Sugai, G., Bullis, M., Sprague, J. R., Bricker, D., \& Kaufman, M. J. (1996). Integrated Approaches to Preventing Antisocial Behavior Patterns among School-Age Children and Youth. Journal of Emotional and Behavioural Disorders, 4(4), 194-209. https://doi.org/10.1177/106342669600400401.

Wolff, J. A., \& Pett, T. L. (2004). Small-firm Performance: Modelling The Role of Product and Process Improvements. Journal of Small Business Management, 44(2), 268-284. https://doi.org/10.1111/j.1540-627X.2006.00167.x.

Zahra, S.A., \& Nielsen, A.P. (2002). Sources of Capabilities, Integration, and Technology Commercialization. Strategic Management Journal, 23(5), 377-398. https://doi. org/10.1002/smj.229. 